\title{
Knowledge, Attitude \& Practice Study on Screening of Cervical Cancer Among Women Visiting A Tertiary Care Center
}

\author{
Archana James Pattupara ${ }^{1 *}$, Niharika Dhiman ${ }^{2}$, Amninder Singh $^{3}$, Jaya Chaturvedi ${ }^{4}$ \\ ${ }^{1}$ Undergraduate MBBS (Bachelor of Medicine \& Bachelor of Surgery), All India Institute of Medical sciences \\ (AIIMS), Rishikesh. \\ ${ }^{2}$ Assistant Professor, Maulana Azad Medical College, New Delhi. \\ ${ }^{3}$ Undergraduate MBBS, AIIMS, Rishikesh \\ ${ }^{4}$ Professor and Head, Department of Obstetrics \&Gynaecology, AIIMS, Rishikesh.
}

Received: October 04 2016; Accepted: October 22 2016; Published: October 252016

*Corresponding author: Archana James Pattupara, Undergraduate MBBS AIIMS Rishikesh Dehradun Uttrakhand, Tel: +91-8126049767;E-mail: archanajp19@yahoo.in

\begin{abstract}
Context: Cervical cancer is the most common cancer among women in India and ranked fourth worldwide. The long precancerous stage of cervical cancer provides a window period for screening and early detection. Evaluation of knowledge and attitude towards them is important for effective implementation of screening programmes especially in a low resource setting. No such studies have been conducted in this region where estimated incidence rate of cervical cancer is quite significant. There is no provision available for mass or regular screening for cervical cancer in the state as well.
\end{abstract}

Aims: To assess the knowledge, attitude and practice towards screening of cervical cancer among women visiting the outpatient clinic.

Settings and Design: A cross-sectional descriptive Knowledge Attitude Practice, (KAP) study including the women who visited the outpatient clinic of All India Institute of Medical Sciences, Rishikesh.

Methods and Material: The principal investigator interviewed 400 women (18 to 65 years) over three months, with a structured validated pre-tested questionnaire. Informed consent was obtained.

Statistical analysis used: The mean age and knowledge- attitude score with standard deviation was calculated using MS Excel. MannWitney test was used to compare scores between plains and hills.

Results: Ninety three percent $(372 / 400)$ of the respondents had no knowledge regarding cervical cancer. The remaining $7 \%(28 / 400)$ had a mean score of $35.60 \%(9.97 / 28)$. There was no significance in the difference in mean scores between respondents from plains and the hills. Only $3.25 \%(13 / 400)$ respondents had knowledge about Pap smear as a screening technique but none had undergone the test voluntarily.

Conclusions: The awareness about cervical cancer and its screening is extremely poor. There is a dire need to generate awareness as accessibility, logistics and education already pose a negative impact in making implementation of screening programmes effective in this low resource setting with a high incidence of cervical cancer.

Keywords: Cervical cancer screening; KAP on cervical cancer; Low resource setting; Uttarakhand;

\section{Introduction}

Cervical cancer is the most common cancer in India and fourth most among women with an incidence of about 528,000 new cases and 266,000 deaths worldwide ${ }^{[1]}$. Out of 445,000 cases from the developing regions, 123,000 cases are from the Indian subcontinent in comparison to 92,000 cases from WHO African region [1].

The mean age of patients with in situ lesions is 15.6 years younger than the age of patients with invasive carcinoma, providing a window for effective screening [2]. In addition to evaluating the infrastructure \& manpower, it is essential to assess the Knowledge, Attitude and Practice (KAP) of clients, before implementing any screening/awareness programme.

Several studies have been conducted worldwide with variable results. While a study from Yemen shows $80.6 \%$ participants with various levels of knowledge, $81.2 \%$ of participants from an Ethiopian study had never heard of Pap smear screening $[3,4]$.

About 861 females might be affected by cervical cancer every year, extrapolating the Age Adjusted Incidence Rates (AAR) of cervical cancer (17.4 per 1 lakh; New Delhi) from the Population Based Cancer Registry (PBCR) on the population of Uttarakhand a low resource setting [5].

Hence, this study aims to assess the knowledge, attitude and practice and help in formulating screening programmes, as scarce data is available and there are no routine screening programmes for prevention of cervical cancer in Uttarakhand, which caters to a population of both plain (68\%) and hilly (32\%) areas[Method

This is a cross-sectional descriptive questionnaire based Knowledge, Attitude and Practice (KAP) study involving females who visited the outpatient clinic over a duration of three months from July 2015 through September 2015. This methodology was found to be apt for a KAP study. 
Assuming that knowledge, attitude, and practice (KAP) regarding cervical cancer screening among females in the general population as $50 \%$, sample size is calculated using the formula:

$$
N=\mathrm{z}^{2} \mathrm{p}_{*}(1-\mathrm{p}) / \mathrm{c}^{2}
$$

where,

\section{$\mathrm{N}=$ sample size}

$\mathrm{z}=$ standard normal deviation at 95\% confidence level [1.96]

$P=$ percentage of primary indicator in decimal [0.5]

$c=$ standard error in decimal [0.05]. The sample size was calculated to be 400 .

Out of the 403 subjects approached, 400 responded positively to the study.

The study received Institutional Ethical Committee clearance.

Study tool: A structured pre-tested and validated questionnaire was used. It consisted of three sections.

Section 1: Demo graphic profile [6].

Section 2: To assess the knowledge and attitude [20].

Section 3: To assess the practice [11].

\section{Data collection}

The purpose of the study was explained to all the participants. Informed written consent was obtained. Those who consented were interviewed with the questionnaire by the principal investigator. The confidentiality and anonymity of the respondents were maintained.

Each correct response was given a score of 1.Cumulative score was added for each participant with maximum being 28 points. The mean score with standard deviation was calculated using MS Excel. Mann-Whitney test was applied (as the sample size with positive responses was less than 20 in the study) to determine the significance in difference of scores in between respondents from plains and hills.

\section{Results}

The mean age of respondents was $37.84 \pm 11.20 \mathrm{yrs}$. Majority $(63 \%, 251 / 400)$ of the subjects were in the age group of $28-47$ years and $82.25 \%(329 / 400)$ were sexually activity. The agewise distribution of number of respondents are given in table.1

Knowledge:_About $73.75 \%(295 / 400)$ of the respondents have never heard of cervical cancer and 19.25\% (77/400) have just heard of it but have no knowledge regarding cervical cancer. It is only the remaining seven percent $(28 / 400)$ who have some knowledge about carcinoma cervix of which only $3.25 \%(13 / 400)$ know about screening techniques.

The response given by the seven percent (28 subjects), to questions pertaining to knowledge regarding cervical cancer, its risk factors, symptoms and screening techniques are given in tables 2. Genital tract infections and multiple sex partners were considered important risk factors by $40 \%$ of subjects and lower abdominal pain and contact bleeding were considered as more common symptoms of cervical cancer by $42 \%$.

Even though 13 females (03.25\%) knew about Pap smear, none $(0 / 13)$ were aware of the recommended interval between regular screenings.

The average knowledge-attitude score of 28 subjects was $35.60 \%(9.96 / 28)$. The age wise distribution of score is given in table.3.

\begin{tabular}{|c|c|}
\hline Table 1: Age frequency \\
\hline Years & \%(number) \\
\hline $18-27$ & $17.50 \%(70)$ \\
\hline $28-37$ & $3 v 8.00 \%(152)$ \\
\hline $38-47$ & $24.75 \%(99)$ \\
\hline $48-57$ & $11.50 \%(46)$ \\
\hline$>57$ & $08.25 \%(33)$ \\
\hline
\end{tabular}

\section{Table 2}

Knowledge regarding cervical cancer

Correct response $(\mathrm{n}=\mathbf{2 8})$ $\%$ (number)

Q. Is cervical cancer preventable? $78.57(22)$

Q. Can cervical cancer be detected at early stage?

64.28(18)

Q. Is cervical cancer curable?

$85.71(24)$

Q. Can Cervical cancer present without symptoms in early stage? $46.64(13)$

Q. Is there any vaccine for prevention of cervical cancer?

$25.00(07)$

Response to risk factors for cervical

Correct response $(\mathrm{n}=28)$ cancer $\%$ (number)

a) Multiple sex partner 39.28(11)

b) Early coitus 21.42(06)

c) Family history $35.71(10)$

d) Smoking 25.00(07)

e) Prolonged OCP use $35.71(10)$ f) Genital infections 42.28(12) g) Don't know 14.28(04) Cervical cancer can present as :

Correct response $(\mathrm{n}=28)$ $\%$ (number)

a) Intermittent bleeding 32.14 (09)

b) Bleeding after intercourse 42.85 (12)

c) Discharge $\quad 39.28(11)$

\begin{tabular}{l|l}
\hline d) Dyspareunia & $28.57(08)$ \\
\hline
\end{tabular}

\begin{tabular}{ll|l}
\hline e)Bleeding and spotting after & $39.28(11)$
\end{tabular}

f) Lower abdominal pain $\quad 42.85$ (12)

\begin{tabular}{l|l}
\hline g) Don't know & $03.57(01)$
\end{tabular}

Screening methods for cervical cancer

Correct response $(n=28)$ $\%$ (number)

a) Pap smear $\quad 46.42 \%(13)$

b)VIA,VILLI, Colposcopy, HPV detection 
The average score of subjects from plain and hilly areas were compared Table.4. Mann Whitney test was applied and there is no significance in the difference of scores between subjects from hilly and plain regions.

Attitude: The attitude towards screening techniques was evaluated as shown in table.5. Around 40\% (5/13) considered Pap smear screening essential only if symptomatic.

Practice: None of the subjects had undergone a Pap smear screening voluntarily in their life time. Four subjects had undergone Pap smear who had consulted for gynecological complaints which was followed by hysterectomy in all of them (diagnosis unknown).The reason for not getting the test done was that they never considered it important.

\section{Discussion}

Though the average KAP scores of plain vs. hills is not sigs and performed regularly even if consulting for other gynecological or

Table 3:

\begin{tabular}{|c|c|c|}
\hline $\begin{array}{l}\text { Age group } \\
\text { (years) }\end{array}$ & $\begin{array}{l}\text { Average score } \\
\% \text { (number*) }\end{array}$ & $\begin{array}{l}\text { Respondents } \\
(n=28)\end{array}$ \\
\hline $18-27$ & $35.00(9.8)$ & 5 \\
\hline $28-37$ & $43.39(12.14)$ & 13 \\
\hline $38-47 v$ & $34.28(9.59)$ & 5 \\
\hline $48-57$ & $39.28(10.99)$ & 2 \\
\hline$>57$ & $26.07(07.29)$ & 3 \\
\hline Average score & $35.60(9.97)$ & \\
\hline
\end{tabular}

Table 4 :

\begin{tabular}{|l|l|ll}
\hline Topography & $\begin{array}{l}\text { Total } \\
\text { participants } \\
\text { N=400 }\end{array}$ & $\begin{array}{l}\text { No:of } \\
\text { participants } \\
\text { withknowledge } \\
\text { N= 28 }\end{array}$ & $\begin{array}{l}\text { Average score } \\
\text { \%(points*) }\end{array}$ \\
\hline Plains & 321 & 19 & $37.96(10.62)$ \\
\hline Hillyregions & 79 & 9 & $38.46(10.76)$ \\
*maximum score $=28$ & & & \\
\hline
\end{tabular}

Table 5:

\begin{tabular}{|l|l|}
\hline Attitude towards PAP smear & $\begin{array}{l}\text { Correct response } \\
\text { \%(number) }\end{array}$ \\
\hline Should be screened if symptomatic? & $38.46 \%(05)$ \\
\hline It causes genital tract infection? & $15.38 \%(02)$ \\
\hline It can be done during pregnancy? & $07.69 \%(01)$ \\
\hline It is only for elderly females & $07.69 \%(01)$ \\
\hline
\end{tabular}

obstetric diseases. For mass screening VIA can be opted being cheap and provides immediate results. The health care facilities are comparatively weak in the hilly terrains. The incidence rates of cervical cancer are still not exactly known, as there are no Rural Based Cancer Registries especially for the hills. Accessibility remains the major barrier in generating awareness and in carrying out screening programmes in these rural and hilly region with scattered population. Health campaigns can be conducted only during a few months when the places are accessible because of the extreme weather conditions.Hence, programmes in this region have to be implemented differently from that of urban/plain areas, when accessible \& in coordination with the local health workers.

\section{Conclusion}

The awareness about cervical cancer and screening techniques are extremely poor in this part of the country. There is a dire need to generate awareness and formulate plans for implementation of screening programs in the most cost effective and feasible way, ensuring maximum community participation. The requirements for implementing programmes in the hilly rural areas are different from urban \& plains, in terms of logistics \& accessibility. Therefore special efforts are required to implement awareness and screening campaigns in these areas.

\section{Declarations}

\section{Ethical approval}

Approval obtained from Institutional Ethics Committee (IEC), All India Institute of Medical Sciences, and Rishikesh. IEC code: 70/STS/2015.

\section{References}

1. Globocan 2012: WHO certified International agency for research on cancer, Cervical cancer: Estimated incidence, mortality and prevalence worldwide. 2012.

2. Bapsy PP, Jain A. Gynaecological malignancies; API Textbook of Medicine, $9^{\text {th }}$ Ed.Jaypee Brothers Medical Publishers (P) Ltd, New Delhi,2012; P. 1606

3. Abdul-Aziz M.Knowledge, Attitude and Practice towards Cervical Cancer among Reproductive Health Clients at the University of Science \& Technology Hospital-Sana'a in Yemen; YJMS. 2012;6(1) .

4. Terefe Y, Gaym A. Knowledge, attitude and practice of screening for carcinoma of the cervix among reproductive health clients at three teaching hospitals, Addis Ababa, Ethiopia. EJRH, 2008;2.

5. A. Nandakumar, T. Ramnath, Chaturvedi M. The magnitude of cancer cervix in India; National Cancer Registry Programme (ICMR), Bangalore, India; Indian J Med Res 130,2009;:219-221.

6. Uttarakhand population Census data, 2011; Census Organization of India. 